Review

\title{
The Role of Short-Chain Conjugated Poly-(R)-3-Hydroxybutyrate (cPHB) in Protein Folding
}

\author{
Rosetta N. Reusch \\ Department of Microbiology and Molecular Genetics, Michigan State University, East Lansing, \\ MI 48824, USA; E-Mail: rnreusch@msu.edu; Tel.: +1-517-349-3544; Fax: +1-517-353-1793
}

Received: 1 April 2013; in revised form: 9 May 2013 / Accepted: 9 May 2013 /

Published: 23 May 2013

\begin{abstract}
Poly-(R)-3-hydroxybutyrate (PHB), a linear polymer of $R$-3-hydroxybutyrate $(R-3 \mathrm{HB})$, is a fundamental constituent of biological cells. Certain prokaryotes accumulate PHB of very high molecular weight (10,000 to $>1,000,000$ residues), which is segregated within granular deposits in the cytoplasm; however, all prokaryotes and all eukaryotes synthesize PHB of medium-chain length ( $\sim 100-200$ residues) which resides within lipid bilayers or lipid vesicles, and PHB of short-chain length $(<12$ residues) which is conjugated to proteins (cPHB), primarily proteins in membranes and organelles. The physical properties of $\mathrm{CPHB}$ indicate it plays important roles in the targeting and folding of cPHB-proteins. Here we review the occurrence, physical properties and molecular characteristics of $\mathrm{cPHB}$, and discuss its influence on the folding and structure of outer membrane protein A (OmpA) of Escherichia coli.
\end{abstract}

Keywords: poly-(R)-3-hydroxybutyrate; cPHB; PHBylation; protein-folding; protein-targeting

\section{Introduction}

Poly-(R)-3-hydroxybutyrate (PHB), a linear polymer of $R$-3-hydroxybutyrate (R-3HB) (Figure 1), was first discovered in granular inclusion bodies within the cytoplasm of Bacillus megaterium in the mid 1920s by Maurice Lemoigne [1]. Similar PHB-containing granules were subsequently observed in other eubacteria and archaea, principally those that inhabit soil and water ecosystems [2-4] (Figure 2A). The granules frequently include some $R$-3-hydroxyvalerate and other hydroxy-acids, and thus they are often referred to as polyhydroxyalkanoates (PHA). The polymers in these complex subcellular organelles, known as carbanosomes, are very long-chain (10,000 to $>1,000,000$ residues), and are covered by a layer of lipids and proteins, which include enzymes involved in PHB synthesis 
and degradation [5-7]. PHB is accumulated by these prokaryotes when carbon sources are freely available but other nutrients are limited, thus PHB is considered to serve as a carbon and energy store in these organisms. The granules have attained considerable commercial importance as ingredients of biodegradable plastics. Recently, Elustondo et al. [8], using fluorescence spectroscopy, identified PHB-rich granules, which resembled bacterial carbanosomes and did not co-localize with mitochondria, lysosomes or endoplasmic reticulum, in the cytoplasm of cultured mammalian cells. It was suggested that the PHB may serve as a carbon and energy store for these cells. The identity of PHB was confirmed by a marked decrease in fluorescence intensity when the samples were treated with PHB depolymerase (PhaZ); however, the molecular weight of the polymer has not yet been determined.

Figure 1. Chemical structure of poly-(R)-3-hydroxybutyrate (PHB).

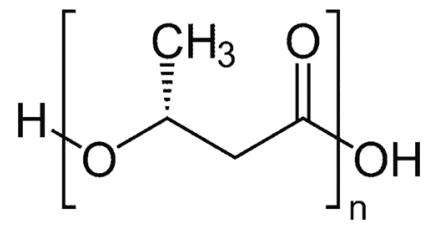

Figure 2. Classes of poly-(R)-3-hydroxybutrate. (A) Storage PHB. Ultrathin section of an Azotobacter chrococcum cell showing granules of PHB surrounded by a membrane (X 56,200) From Nuti et al. [4]; (B) Medium-chain length PHB. Sketch of PHB molecule surrounding and noncovalently associated with a molecule of calcium polyphosphate in the bilayer; (C) Short-chain PHB covalently attached (cPHB) to protein (grey).

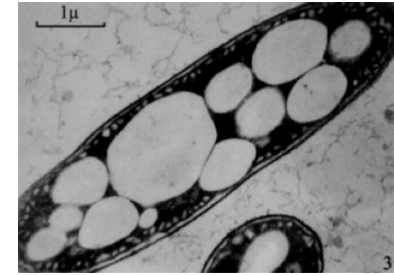

(A)

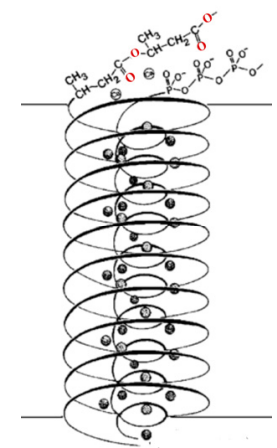

(B)

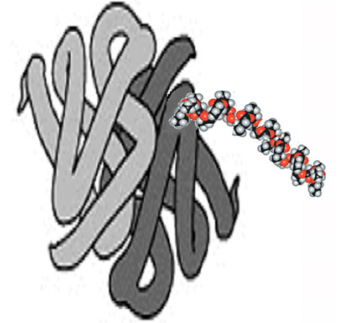

(C)

PHB of medium-chain length was first discovered in the cytoplasmic membranes of genetically-competent bacteria by Reusch and Sadoff in 1983 [9]. Medium-chain PHB typically consists of 100-200 residues, but it may contain fewer residues due to the lability of ester bonds. Medium-chain PHB, like storage PHB, is insoluble in water and soluble in chloroform, and non-covalently associated with other molecules. The medium-chain length polyester was found in the membranes of competent bacteria which also accrue high molecular weight storage PHB - Azotobacter vinelandii and Bacillus subtilis - but it was also unexpectedly present in the membranes of competent bacteria-Haemophilus influenzae and Escherichia coli-which do not accumulate PHB granules [9,10]. In 1989, medium-chain length PHB was recovered from membranes, mitochondria and microsomes of eukaryotes [11], and in 1992 from lipoproteins (very low density and low density (VLDL and LDL) of human plasma [12]. The identity of medium-chain length PHB in 
representative prokaryotic and eukaryotic organisms was confirmed by ${ }^{1} \mathrm{H}-\mathrm{NMR}$ spectroscopy by Reusch [13] in 1992 and corroborated by Seebach et al. [14] in 1994. Medium-chain length PHB has been found associated with inorganic polyphosphate in noncovalent complexes (Figure 2B) that are postulated to play a role in transbilayer transport of cations [15-17] and deoxyribonucleic acids [18-20].

In 1996, Huang and Reusch [21] discovered short-chain PHB ( $\leq 10$ residues) covalently bound to specific proteins in the membranes and the cytoplasm of E. coli cells (Figure 2C). This short-chain conjugated PHB has been termed cPHB. It is generally thought to consist of $<20$ residues but this remains unclear due to the lability of the ester bond and the paucity of samples examined to date. Unlike storage PHB that is segregated within cytoplasmic granules and medium-chain PHB that is "dissolved" in lipid environments, cPHB has been found in all cell compartments of prokaryotes and eukaryotes and in intracellular fluids [22-28]. Indeed, the majority of PHB in cells that do not accumulate long-chain storage PHB is cPHB. Significantly, unlike storage PHB and medium-chain length PHB, cPHB cannot be isolated from cells or organelles by extraction with chloroform. The ubiquitous occurrence of the medium-chain and short-chain polyester, suggests that PHB, like polyisoprenoids, polypeptides, polysaccharides, and polynucleotides, is a fundamental constituent of biological cells. Since its synthesis requires only acetate and reducing potential, both of which were available in the primordial soup, the structurally simple PHB may have been the earliest of the biological organic polymers [21,29].

\section{Synthesis of PHB}

$R$-3-hydroxybutyrate (R-3HB) is a well-known metabolite in fatty acid synthesis in both prokaryotes and eukaryotes $[2,3,30]$. The synthesis of $R-3 \mathrm{HB}$ begins with the condensation of two molecules of acetyl-CoA to form acetoacetyl-CoA by a ketothiolase enzyme. In prokaryotes, this intermediate is subsequently reduced with NADPH to $R-3-\mathrm{HB}-\mathrm{CoA}$ by acetoacetyl-CoA reductase, and $R-3-\mathrm{HB}-\mathrm{CoA}$ may then be polymerized to form PHB by the enzyme PHB synthase (Figure 3 ). In eukaryotes, 3-hydroxy-3-methylglutaryl-CoA synthase (HMG synthase) catalyzes the condensation of acetoacetyl-CoA with a third acetyl-CoA to form 3-hydroxy-3-methylglutaryl-CoA (HMG-CoA). The enzyme HMG-lyase then catalyzes the decomposition of HMG-CoA to form acetoacetate and acetyl-CoA, and acetoacetate is further reduced with NADH by $R-3-\mathrm{HB}$ dehydrogenase to form $R$-3-HB (Figure 3). Enzymes that polymerize $R$-3-hydroxybutyrate or its CoA ester have not yet been identified in eukaryotes.

\section{Physical Properties of PHB}

PHB consisting of more than six residues is insoluble in water and soluble in chloroform [2]. The PHB molecule is amphiphilic-hydrophobic methyl groups alternate with hydrophilic carbonyl ester groups (Figure 1); accordingly, the methyl groups may engage in hydrophobic interactions and the ester carbonyl oxygens may serve as hydrogen-bond acceptor or as ligands for coordinate bonds to cations. Moreover, polyesters such as PHB, in contrast to polyamides and polypeptides, have highly flexible backbone structures, since they lack the stabilizing element of internal hydrogen bonds and the rigidity of a peptide bond. The extremely high flexibility of the PHB backbone at physiological temperatures has been amply demonstrated by Seebach et al., using circular dichroism and 
fluorescence (FRET) measurements [31], nuclear magnetic resonance (NMR) spectroscopy [32,33] and molecular dynamics simulations [34]. However, it is important to note that the glass temperature of PHB is $\sim 10{ }^{\circ} \mathrm{C}$, so that the PHB backbone becomes increasingly more rigid as temperatures are lowered below the physiological range.

Figure 3. Biosynthetic pathways for PHB metabolites in prokaryotes and eukaryotes. In all organisms, acetoacetyl-CoA is formed by condensation of two acetyl-CoA. In prokaryotes (right), acetoacetyl-CoA is reduced by NADPH to $R$-3-hydroxybutyryl-CoA, which is then polymerized to PHB. In eukaryotes (left), a third acetyl-CoA condenses with acetoacetyl-CoA to form 3-hydroxy-3-methylglutaryl-CoA (HMG-CoA), which is subsequently decomposed to acetoacetate and acetate. Acetoacetate is then reduced by NADH to $R$-3-hydroxybutyrate.

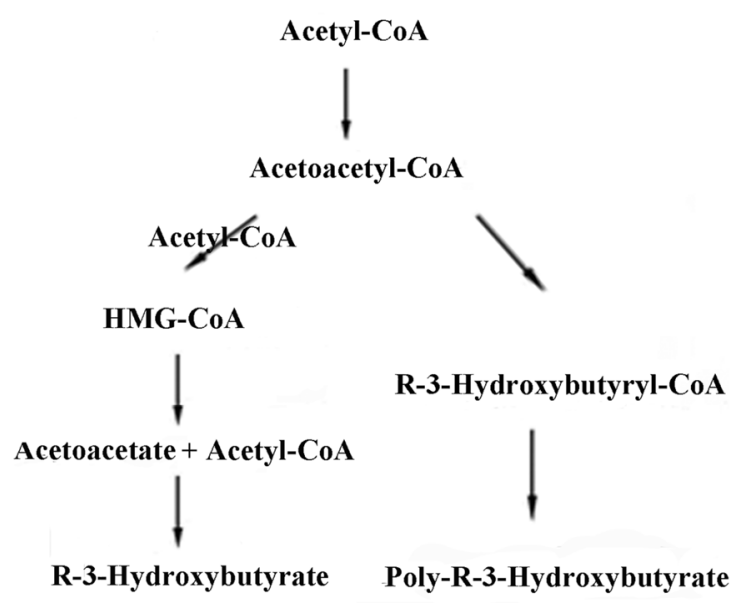

PHB also has uncommon solvating capacity. It may be unique among biological polymers in having the structural features common to a small group of synthetic polymers, known as polymer electrolytes [35-37] that are distinguished by their ability to "dissolve" salts. Significant characteristics of this class of polymers are (1) flexible backbones with low barriers to bond rotation to ease segmental motions of the polymer chain; (2) heteroatoms, such as ester carbonyl oxygens, that have sufficient electron donor power to form coordinate bonds with cations; (3) a suitable distance between the electron donating groups to permit the formation of multiple intra-polymer coordinate bonds to cations. The stability of such polymer salt complexes is enhanced by the entropic advantage known as the "polymer effect", attributable to the cooperative effect of neighboring ligands attached to a common backbone.

PHB "dissolves" salts by encircling them and replacing the water of hydration surrounding the cation with coordinate bonds to its ester carbonyl oxygens. The ability of PHB to solvate salts is however limited. Ester carbonyl oxygens are weak Lewis bases of low polarity and hence PHB form coordinate bonds only with hard cations that have large solvation energies, such as the four major physiological cations, $\mathrm{Na}^{+}, \mathrm{K}^{+}, \mathrm{Mg}^{2+}$, and $\mathrm{Ca}^{2+}$. Moreover, as an aprotic polymer, $\mathrm{PHB}$ does not have hydrogen-bond donating groups that are needed to solvate anions [35-37]. Accordingly, PHB "dissolves" salts composed of hard cations and large anions with diffused charges that require little solvation, and may thereby serve to partition these salts into lipid bilayers or hydrophobic regions of 
proteins. This capacity of PHB has been well established experimentally. Seebach et al. [38] have found that the triolide of R-3HB forms crown ester complexes with alkali metals; Burger and Seebach [39] have shown that oligomers of R-3HB transport alkali and alkaline earth salts across methylene chloride layers in U-tubes; Seebach et al. [40] have demonstrated that PHB of 16 residues or multiples of 16 residues up to 96 residues form channels in planar lipid bilayers, and Fritz et al. [41] have described the gradient-driven transport of $\mathrm{Ca}^{2+}$ into liposomes by $\mathrm{R}-3 \mathrm{HB}$ oligomers.

\section{4. cPHB-Proteins}

It is increasingly apparent that cPHB-proteins are ubiquitous in biological cells, both prokaryotic and eukaryotic [8,11-14,28,42-44]. However, cPHB has remained largely unnoticed because, unlike the highly-visible phase-bright PHB granules, cPHB is sparse and obscure. Its exceptionally flexible backbone and lack of unusual atoms or functional groups makes cPHB nearly invisible in X-ray structures in which it may resemble detergent or lipid molecules. Whereas storage PHB and medium-chain length PHB are insoluble in water and soluble in chloroform, the solubility of a cPHB-protein depends on the nature of the protein itself and on the extent of cPHB modification. However, within a given protein, cPHB significantly alters the hydrophobicity of the protein segments to which it is attached and thereby influences their location within the mature protein.

There are a number of ways in which the functional groups of cPHB may interact noncovalently with protein segments. Since the cPHB molecule is both highly flexible and amphiphilic, cPHB can adjust or reverse the polarity of peptide segments or act as an intermediary between polar segments and the bilayer (Figure 4) [44]. When the methyl groups of cPHB form hydrophobic bonds to nonpolar peptide residues, its ester carbonyl oxygens form a hydrophilic surface that may associate with polar molecules. Conversely, when the carbonyl oxygens of PHB act as hydrogen-bond acceptors or form coordinate bonds to bridging cations of polar peptides, its methyl groups form a hydrophobic surface that may promote movement of the peptide into the protein interior or assist its insertion into a phospholipid bilayer. Individually, such noncovalent bonds are weak, but the frequency at which the methyl groups and ester carbonyl oxygens repeat along the cPHB backbone allows each polymer molecule to have multiple interactions. The number and strength of these bonds would be determined by the primary structure and three-dimensional geometry of the protein at the binding site(s). The tenacity of the bonding, as evidenced by its ability to withstand heating in sodium lauryl sulfate, extraction with warm chloroform, and proteolysis, suggests that there is also a covalent bond between an amino acid residue and the terminal hydroxy group or S-CoA group of cPHB. This covalent attachment of cPHB is known as PHBylation.

Although the cPHB backbone is highly flexible at physiological temperatures, it becomes increasingly more rigid as temperatures approach the glass temperature. As a consequence, cPHB-modified proteins would fold very slowly or be unable to fold into their native conformations when maintained below physiological temperatures. The presence of cPHB may also render protein function(s) highly sensitive to temperature in this range. For example, Zakharian et al. [42,43] found that a member of the transient receptor potential (TRP) channel family of the melastatin subgroup, TRPM8, which is a major sensor for cold temperatures in the peripheral nervous system, is significantly modified by cPHB. 
Figure 4. Sketch illustrating possible modes of noncovalent binding of cPHB to hydrophobic (shaded) and polar (dotted) region in polypeptides, thereby reversing their polarity. From Reusch and Gruhn, (1997) [44].
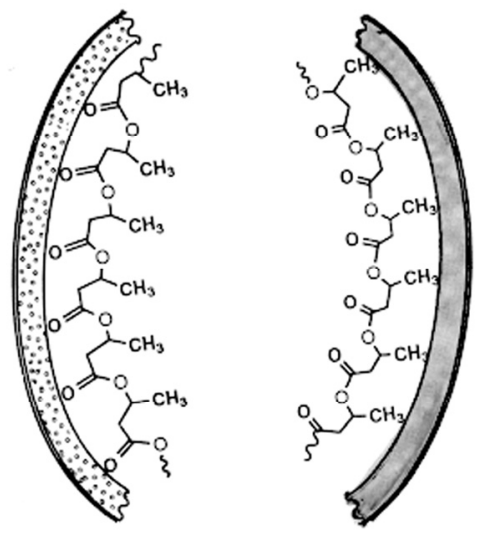

\section{Identification of cPHB}

cPHB may be most easily and sensitively detected by Western blot analysis using anti-PHB IgG [44]. cPHB may also be detected and estimated by a chemical assay in which the polymer is converted via $\beta$-elimination to crotonic acid by heating in concentrated sulfuric acid; crotonic acid may then be isolated and assessed by high pressure liquid chromatography $[21,45]$. The ${ }^{1} \mathrm{H}-\mathrm{NMR}$ resonances of $\mathrm{PHB}$ are distinctive (Figure $5 \mathrm{~A}$ ), but the concentration of cPHB in proteins is very low so that this method requires extensive proteolysis and concentration of the cPHB [46]. Thus far, cPHB has been removed from its complexes with proteins only by treatments which effect hydrolysis of the ester bonds, i.e., heating in dilute acid or refluxing in methanol:chloroform mixtures [14]. cPHB-peptides may also be recognized by MALDI MS [26] (see Figure 6 below).

Figure 5. (A) ${ }^{1} \mathrm{H}$ NMR spectra of PHB from Alcaligenes. From Reusch (1992) [13]; (B) ${ }^{1} \mathrm{H}$ NMR spectra of the $\mathrm{CHCl3}: \mathrm{CH} 3 \mathrm{OH}$ (9:1) extract of the ribosomal fraction of $E$. coli JM101. The sample shows the characteristic methylene and methine protons of PHB; the methyl protons are hidden under resonances of impurities. Assignments: methylene protons split into an octet at 2.42-2.62 ppm, JAX 5.7, JBX 15.5; methane protons form a multiplet centered at $5.23 \mathrm{ppm}$. The assignments were confirmed by selective decoupling of the methine resonances. From Huang and Reusch 1996 [21].

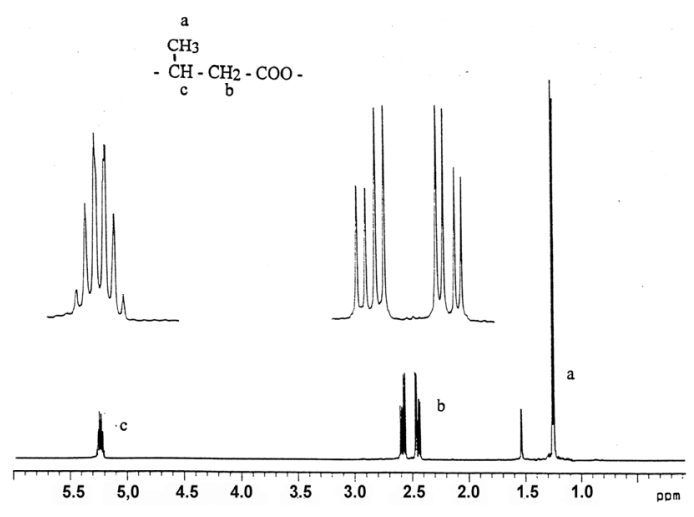

(A)

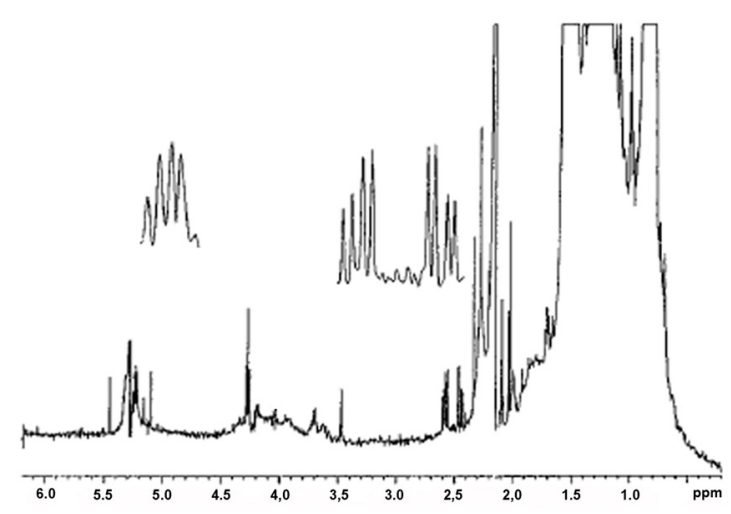

(B) 
Figure 6. MALDI-MS of segment 162-174 of OmpA. Peptide LSLGVSYRFGQGE (162-174), obtained by cyanogen bromide and Staphylococcus aureus Glu-C digestion of wild-type OmpA. Matrix: a-cyano-4-hydroxycinnamic acid. MS analysis was performed using a Voyager Elite (Applied Biosystems) mass spectrometer in linear positive mode with a 50-ns delay. Laser strength was set to 1700 and low mass gate was set at 1000 . Upper panel: initial spectrum. Lower panel: spectrum after $\sim 3$ additional seconds of the laser beam. From Xian et al. (2007) [26].
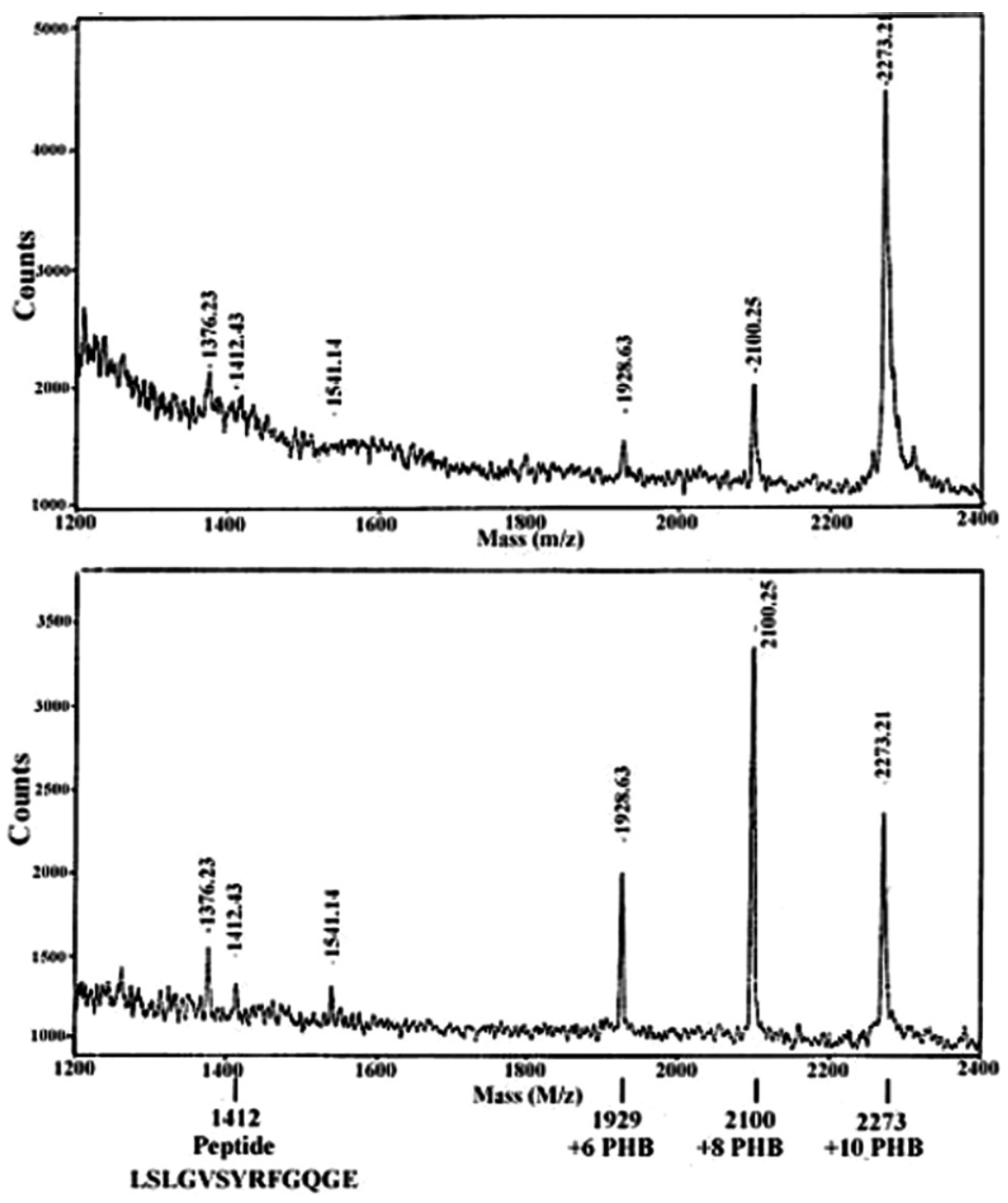

\section{6. cPHB-Proteins in Escherichia coli}

cPHB-proteins have been most extensively examined in E. coli. It is estimated that cPHB comprises $0.36 \%-0.55 \%$ of the dry weight of $\log$-phase E. coli cells [21]. The cPHB-proteins are widely distributed within the cell. Western immunoblots, probed with polyclonal anti-PHB IgG, revealed cPHB-polypeptides in all cell fractions. Surprisingly, the majority of the cPHB-proteins (over 80\%) are located in the cytoplasm, with the largest concentration in the ribosomal fraction. The identity of ribosome-associated cPHB has been confirmed by both chemical assay and ${ }^{1} \mathrm{H}-\mathrm{NMR}$ spectroscopy (Figure 7B) [21]. Some of the cPHB-proteins of E. coli that have been identified thus far by two-dimensional gel electrophoresis followed by Western blot analysis with anti-PHB IgG are listed in Table 1. 
Figure 7. cPHB synthase activity in centrifugal fractions of E. coli BW25113 lysates. S, supernatant; P, pellet. Late log-phase cells were lysed by ultrasonication. The low-speed pellet (P3K) was discarded and the supernatant (S3K) was separated into the following density fractions: envelope fraction (P18K), cytoplasm (S18K), ribosomal fraction (P45K), and cytosolic fraction (S45K). PHB synthase activity was assayed in each fraction by following the conversion of water-soluble ${ }^{14} \mathrm{C}-3-\mathrm{HB}-\mathrm{CoA}$ into TCA-insoluble oligomers. Insert shows distribution of activity in $\mathrm{P} 18 \mathrm{~K}$ fractions (envelope fractions). CM, cytoplasmic membrane; Per, periplasm; OM, outer membrane. Specific activity; counts per minute per mg protein. From Dai and Reusch [47].

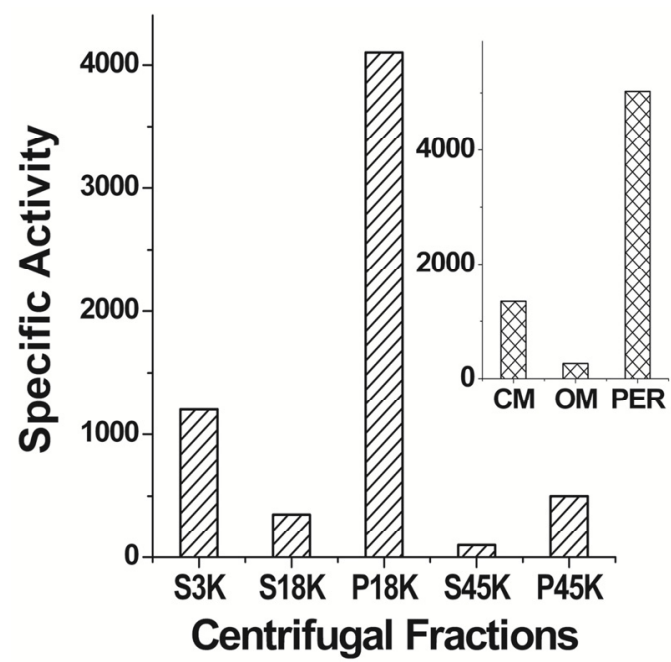

Table 1. cPHB proteins in E. coli lysates were identified by two-dimensional electrophoresis followed by Western blot analysis using anti-PHB IgG. OM-outer membrane; $\mathrm{CM}$ - cytoplasmic membrane.

\begin{tabular}{cccc}
\hline Protein & MW kDa & Gene & Cellular location \\
\hline OmpA & 37.2 & ompA & OM \\
OmpF & 39.3 & ompF & OM \\
OmpC & 40.3 & ompC & OM \\
OmpW & 22.9 & yciD & OM \\
Braun's Lipoprotein & 7.2 & lpp & OM \\
ATP synthase, $\beta$ subunit & 50.3 & atpD & CM \\
GroEL & 57.1 & mopA & CM \\
EF-Tu & 43.2 & tufA tufB & CM \\
EF-TS & 30.2 & tsf & Cytoplasm \\
DNAK & 69.0 & dnaK & Cytoplasm \\
L7/L12 & 12.2 & $r p l L$ & Cytoplasm \\
S1 & 61.1 & $r p s A$ & Cytoplasm \\
H-NS & 15.4 & $h n s$ & Cytoplasm \\
RNA polymerase, $\alpha$ subunit & 150.6 & rpoA & Cytoplasm \\
\hline
\end{tabular}

It has been proposed that two pathways - short-fatty-acid catabolism (atoDAEB operon) and fatty-acid metabolism - participate in the synthesis of cPHB in E. coli through the involvement of the AtoSC signal-transduction system [48-50]. Rychlewski et al. [51] used structural similarity with 
known polymerases and their characteristic GXCXG sequence to identify three potential cPHB polymerases in E. coli-a cytoplasmic polymerase, ysgA, and two other polymerases of unknown cellular location, ycjY and yghX. Dai and Reusch [47] found that cPHB polymerase activity is particularly strong in the periplasm, which displays $\sim 75 \%$ of the total activity (Figure 7 ). They identified one periplasmic cPHB polymerase as ydcS, a putative periplasmic-binding protein of an ABC transporter system, ydcSTUV [52]. The outer membrane of a ydcS deletion mutant of E. coli contained $\sim 30 \%$ less $\mathrm{cPHB}$ than the wild-type protein. The primary structure of ydcS suggests that it may be a member of the $\alpha / \beta$ hydrolase superfamily of proteins [53], which includes class III polyhydroxyalkanoates polymerases as well as lipases and esterases [54].

\section{The Role of cPHB in Folding of Outer Membrane Protein A (OmpA) of Escherichia coli}

The physical properties and distribution of cPHB imply that it plays important roles in protein structure and physiology. The best example to-date of the influence of cPHB on protein targeting and protein folding is the outer membrane protein A (OmpA) of E. coli. OmpA is a major protein of the cell envelope with many functions [55]. It stabilizes the outer membrane [56], acts as a receptor for bacteriophages [57,58], participates in bacterial conjugation [59,60], is a target in the immune response [61], mediates virulence and pathogenicity [62-65] and participates in biofilm formation [66]. In addition, OmpA has served as a paradigm for studies of the biogenesis of outer membrane proteins [67].

\subsection{Structure of OmpA}

The mature conformation of OmpA has been a matter of contention for several decades. A narrow-pore, two-domain structure in which $171 \mathrm{~N}$-terminal residues form a narrow eight $\beta$-barrel pore in the outer membrane and $154 C$-terminal residues form a globular structure that interacts with peptidoglycan in the periplasm has vied with a large-pore, single-domain structure in which all or most of the 325 residues create a large pore in the outer membrane.

A two-domain conformation of OmpA was proposed based on bacteriophage mapping [57,58], proteolysis $[68,69]$, and mutagenesis studies [70,71]. The structure of the narrow pore formed by the $N$-terminal domain — residues 1-171 — has been described by fluorescence, circular dichroism, Raman and NMR spectroscopy [72-75], by X-ray crystallography [76,77], and by molecular simulations [78,79]. The results of these studies indicate that the $N$-terminal domain forms an antiparallel eight-stranded- $\beta$-barrel connected by long, unstructured and mobile loops at the extracellular side and short, tight loops at the periplasmic side. The interior of the $\beta$-barrel, lined with charged and polar residues, encloses several unconnected aqueous cavities. The $C$-terminal domain has been crystallized [80,81] and circular dichroism studies indicate that this domain adopts a mixed alpha/beta secondary structure [82].

The structure of the single-domain large pore is yet unknown; however, a large pore structure is consistent with the known functions of OmpA as a receptor for bacteriophages [57,58] and participant in bacterial conjugation [59,60], both of which imply it forms a pore large enough for the passage of ssDNA. Involvement of the $C$-terminal domain in formation of a large pore is further indicated by studies of OmpA homologues, Pseudomonas aeruginosa OprF by Rawling et al. [83] and Salmonella enterica OmpA (94\% identical to E. coli OmpA) by Singh et al. [84], in which monoclonal antibodies were used to prove that $C$-terminal epitopes of the proteins were exposed on the cell surface of intact bacteria. 
Computer modeling studies have supported the involvement of the $C$-terminal domain in pore formation. Jeanteur et al. [85] predicted two transmembrane $\beta$ - strands within the $C$-terminal domain, and additional $C$-terminal transmembrane segments were predicted by algorithms of Schirmer and Cowan [86] and Ferenci [87]. Stathapoulos [88] constructed a $16 \beta$-barrel structure with eight transmembrane segments in the $C$-terminal domain that is consistent with the varied biochemical, immunological, and genetic topological data concerning OmpA (Figure 8).

Experimental evidence for a large pore structure for OmpA is provided by studies of Sugawara and Nikaido [89,90] which showed that $2 \%-3 \%$ of the molecules form nonspecific diffusion pores of $\sim 1 \mathrm{~nm}$ diameter in liposomes and planar bilayers, and by studies of Arora et al. [91] in which two interconvertible conductance states were observed: a major population of small pores (50-80 pS) and a minor population of large pores $(260-320 \mathrm{pS})$. The large pore conformer was not observed when only the $N$-terminal domain was present, which supports the premise that the $N$-terminal membrane portion of OmpA is sufficient for formation of the small channel whereas the large channels require the presence of both domains. The existence of a large pore structure is further supported by planar lipid bilayer studies of OmpA by Zakharian and Reusch [92,93], which show that large pores ( 450 pS) are the dominant structures (open probability of 0.9 ) at physiological temperature of $37^{\circ} \mathrm{C}$ (see below).

Figure 8. Composite topological structure of OmpA. Left (blue): topological of the $N$-terminal domain of OmpA (residues 1-175), as determined by X-ray crystallography performed by Pautsch \& Schultz [76,77]. Right (green): hypothetical topology of the $C$-terminal domain (residues 175-325), as proposed by Stathopoulos [88]. From Reusch 2012 [94].

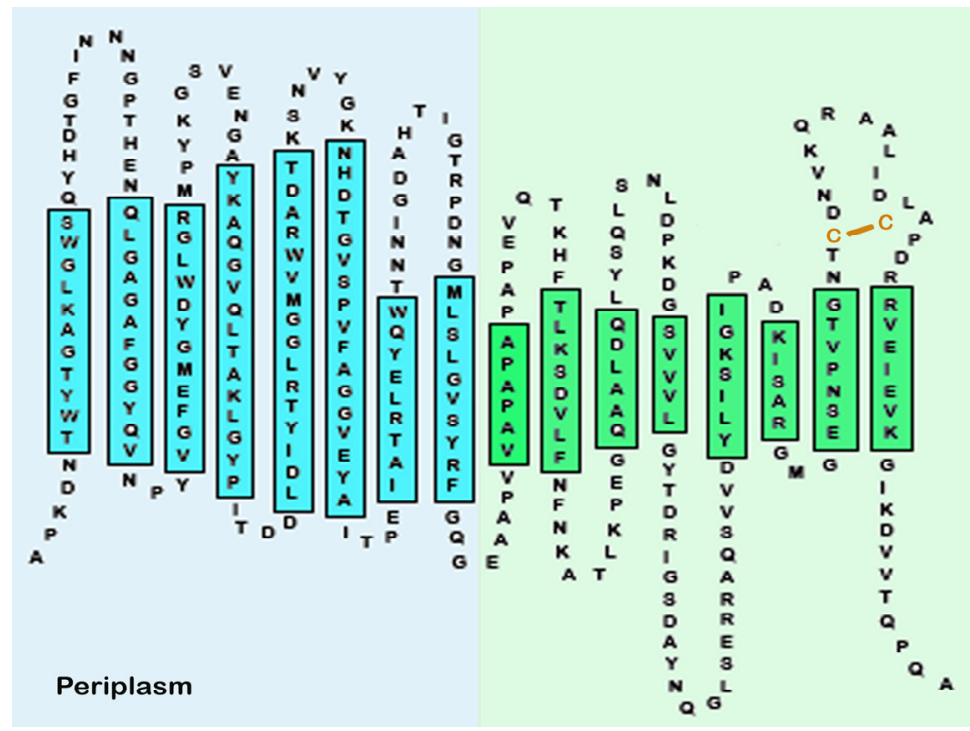

\subsection{Targeting and Folding of OmpA}

OmpA must be transported from the ribosome to the cytoplasmic membrane, conveyed across the cytoplasmic membrane into the periplasm, conducted across the periplasm, inserted into the outer membrane and folded therein in its mature conformation. During this journey, modifications may be made to the protein by cytoplasmic and/or periplasmic enzymes. Studies of OmpA structure have been performed with OmpA obtained by protein overexpression into cytoplasmic inclusion granules or with OmpA directly extracted from the outer membranes of $E$. coli. In both cases, OmpA will have acquired 
modification(s) made to the protein in the cytoplasm but only OmpA extracted from the outer membranes will have acquired any additional modification(s) that may be made in the periplasm.

\subsubsection{From the Ribosome to the Cytoplasmic Membrane}

The OmpA precursor (ProOmpA) is synthesized in the cytoplasm as a 325-residue protein with a 21-residue signal sequence at the amino terminal. Studies by the Henning group [95-99] have demonstrated that residues 163-170 (SLGVSYRF) of the $N$-terminal domain of OmpA, known as the sorting signal, are essential for the integration of OmpA into the outer membrane. When the sorting signal is removed, OmpA remains in the periplasm. Xian et al. [26] established by Western blot immunoassay and chemical assay that both serine residues in segment 162-174 (LSLGVSYRFGQGE) of OmpA are modified by cPHB. The studies further indicated that the serines are modified only when bordered by hydrophobic residues. In the S167G mutant, replacement of either of the hydrophobic residues adjacent to S163-L162 or L164-with glycine prevented cPHB-modification of S163. Similarly, in the S163G mutant, replacement of the hydrophobic residue V166 by glycine inhibited cPHB-modification of S167. Segment 162-174 was modified by cPHB in protein isolated from cytoplasmic inclusion bodies as well as in protein isolated from outer membranes, indicating that the attachment of cPHB takes place in the cytoplasm. The cPHB could not be removed from peptide 162-174 by solvent extraction, suggesting it is covalently attached to the serines at its CoA ester end.

cPHB is not discernible in the Raman or ${ }^{1} \mathrm{H}-\mathrm{NMR}$ spectra [73-75] or X-ray structures [76,77] of the $N$-terminal domains. Due to its low concentrations and highly flexible backbone, cPHB would resemble detergent or lipid molecules in these spectra. However, the modification of OmpA peptide 162-174 by up to 10 R-3HB residues is visible in the MALDI-MS spectra [26] (Figure 6). The lability of the ester bonds of cPHB is indicated by differences between the upper and lower spectra. In the upper spectrum, the molecular ion (1412) is buried in the noise but strong peaks are observed that correspond to covalent attachment of 10, 8, and 6 units of R-3HB. In the lower spectrum, obtained after a few additional seconds of exposure of the sample to the laser beam, the molecular ion has become visible, while the peak attributed to covalent attachment of R-3HB of 10 units has diminished, and peaks attributed to covalent attachment of R-3HB of 8 and 6 units have intensified. The R-3HB units appear to be degraded by the laser in pairs and fewer than $6 \mathrm{R}-3 \mathrm{HB}$ units were not observed. It is interesting to note that the enzymatic degradation of storage PHB also proceeds with the loss of R-3HB dimers [100]. Continued exposure to the laser beam ultimately results in completely degrading the cPHB. The modification of the serines in segment $162-174$ by cPHB is further indicated by MALDI-MS of the double mutant S163G/S167G, which showed a strong peak for the molecular ion and no higher molecular weight peaks attributable to modification by cPHB [26].

Negoda et al. [101] demonstrated the importance of cPHB modification of the sorting signal to the incorporation of OmpA into planar lipid bilayers as a narrow pore at room temperatures (Figure 9). Wild-type OmpA (WT) formed well-structured low-conductance narrow pores (80 $\pm 2 \mathrm{pS}$ ) with high open time ( 0.9). Single serine mutants S163G and S167G, which still contain some cPHB on the sorting signal, retained the ability to form narrow pores in planar lipid bilayers; however, the partial loss of cPHB resulted in significantly lower conductance and open time. The double mutants, S163G/S167G and S163V/S167G, which are completely without cPHB on the sorting signal, 
displayed only trial insertions into the bilayer, which suggests that these mutant proteins are associated with the bilayer and may even lie within it, but are unable to form stable pores. Clearly, the attachment of cPHB to hydrophilic serine residues in the eighth $\beta$-strand decreases the hydrophilicity of this segment and thereby assists in targeting the protein to the bilayer and/or inserting the protein into the bilayer as a narrow pore.

Figure 9. (Left) Representative current traces of OmpA wild-type and mutant OmpA proteins isolated from cytoplasmic inclusion bodies of $E$. coli BL21(DE3) pLysS cells The proteins were incorporated into planar lipid bilayers of 1,2-diphytanoyl-sn-glycero-3phosphocholine (DPhPC) at room temperature between aqueous solutions of $1 \mathrm{M} \mathrm{KCl}$ in $20 \mathrm{mM}$ HEPES, $\mathrm{pH}$ 7.4. Bar at right of the traces indicates the closed state of the channel. Clamping potential was $+100 \mathrm{mV}$ with respect to ground; (Right) Histograms taken from records of $c a .10$ min at room temperature. From Negoda et al. BBA 2010 [101].

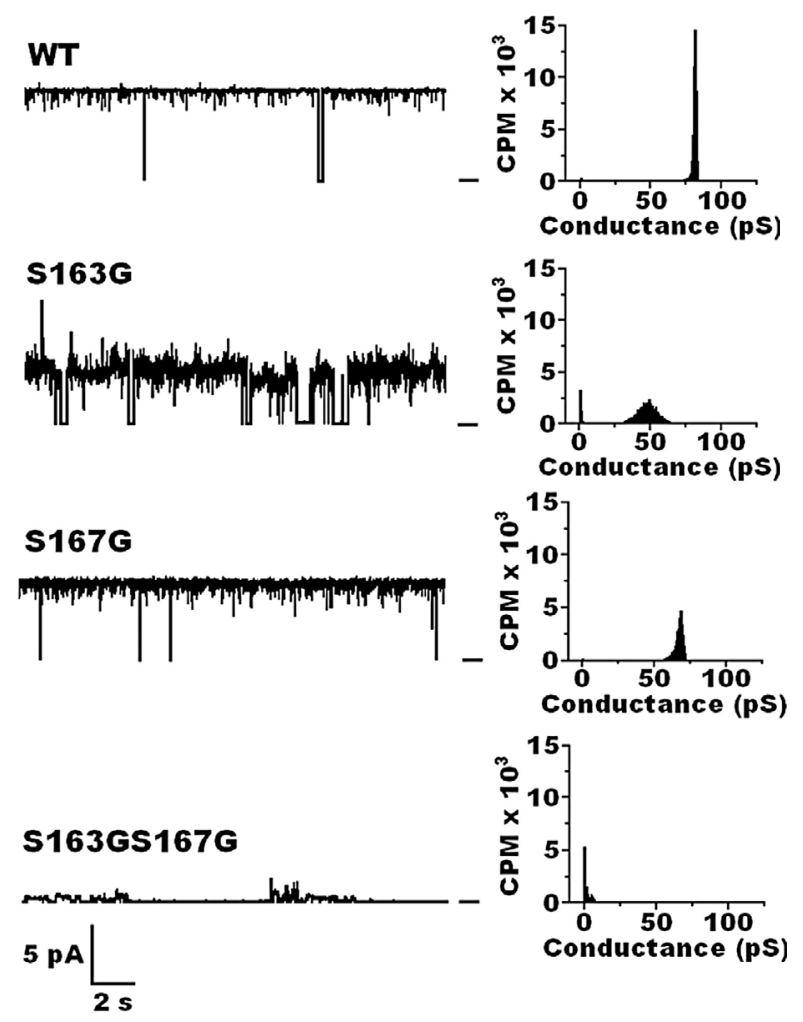

\subsubsection{Across the Periplasm to the Outer Membrane}

After translocation across the cytoplasmic membrane, the signal sequence is cleaved and OmpA, assisted by periplasmic chaperones and lipopolysaccharides, is inserted into the outer membrane and folded into its native form [102-105]. In order to form the large-pore structure, hydrophilic segments of the $C$-terminal domain must insert into the outer membrane bilayer, and this requires an increase in their hydrophobicity. This may be accomplished by the attachment of cPHB to specific amino acids.

Modification of the $C$-terminal domain by cPHB is a decisive event in the translocation and folding of OmpA into the outer membrane in its mature large-pore conformation. Studies by Negoda et al [46]. demonstrated that the $C$-terminal domain of OmpA 264-325 is modified by cPHB and that this modification takes place in the periplasm, i.e., Western Blot and chemical assays indicated that 
segment 264-325 contains cPHB when OmpA is isolated from outer membranes, but not when OmpA is isolated from cytoplasmic inclusion bodies. The identity of cPHB on segment 264-325 of OmpA was confirmed by ${ }^{1} \mathrm{H}-\mathrm{NMR}$. The increased hydrophobicity conferred to this segment by addition of cPHB is indicated by the solubility of segment 264-325 in chloroform when it is obtained from outer membranes, in contrast to its insolubility in chloroform when it is obtained from inclusion granules. The specific residues that are modified by $\mathrm{cPHB}$ within this segment have not been identified. It is also unknown whether other segments of the $C$-terminal domain are modified by cPHB.

Studies by Zakharian and Reusch [92,93] illustrate the importance of temperature in the folding of OmpA into its native large-pore form. They showed that OmpA, whether isolated from outer membranes (M-OmpA) or from inclusion bodies (I-OmpA), forms narrow pores in planar lipid bilayers at room temperatures. However, as temperatures are raised to physiological values, M-OmpA but not I-OmpA undergoes a transition from a narrow low-conductance pore to a large high-conductance pore structure (Figure 10). Further studies [101] indicated that this folding step is steeply temperature-dependent, indicating a high activation energy, estimated as $\sim 139 \mathrm{~kJ} / \mathrm{mol}$, which is indicative of a major conformational rearrangement. The temperature-sensitivity of the cPHB backbone likely contributes to this high energy of activation. In vivo, the folding process may be assisted by chaperones that lower the activation energy.

Figure 10. Representative single-channel current traces of OmpA extracted from outer membranes (M-OmpA) and OmpA extracted from inclusion bodies (I-OmpA) in E. coli BL21(DE3)pLysS cells. M-OmpA. Each protein was isolated with LDS, reconstituted in C8E4 micelles, and incorporated into bilayers of 1,2-diphytanoyl-sn-glycero-3phosphocholine (DPhPC) between aqueous solutions of $20 \mathrm{mM}$ Hepes ( $\mathrm{pH} 7.4)$ and $1 \mathrm{M}$ $\mathrm{KCl}$ at $22{ }^{\circ} \mathrm{C}$. (A) M-OmpA and I-OmpA at $22{ }^{\circ} \mathrm{C}$; (B) M-OmpA and I-OmpA at $22{ }^{\circ} \mathrm{C}$ after incubation at $40{ }^{\circ} \mathrm{C}$ for $2 \mathrm{~h}$. The closed state is indicated by the bar at the right of each trace. The clamping potential was $+100 \mathrm{mV}$ with respect to ground (trans). The corresponding histograms from $1 \mathrm{~min}$ of continuous recording show the distribution of conductance magnitudes. CPM, counts per minute. From Negoda et al. FEBS 2010 [46].

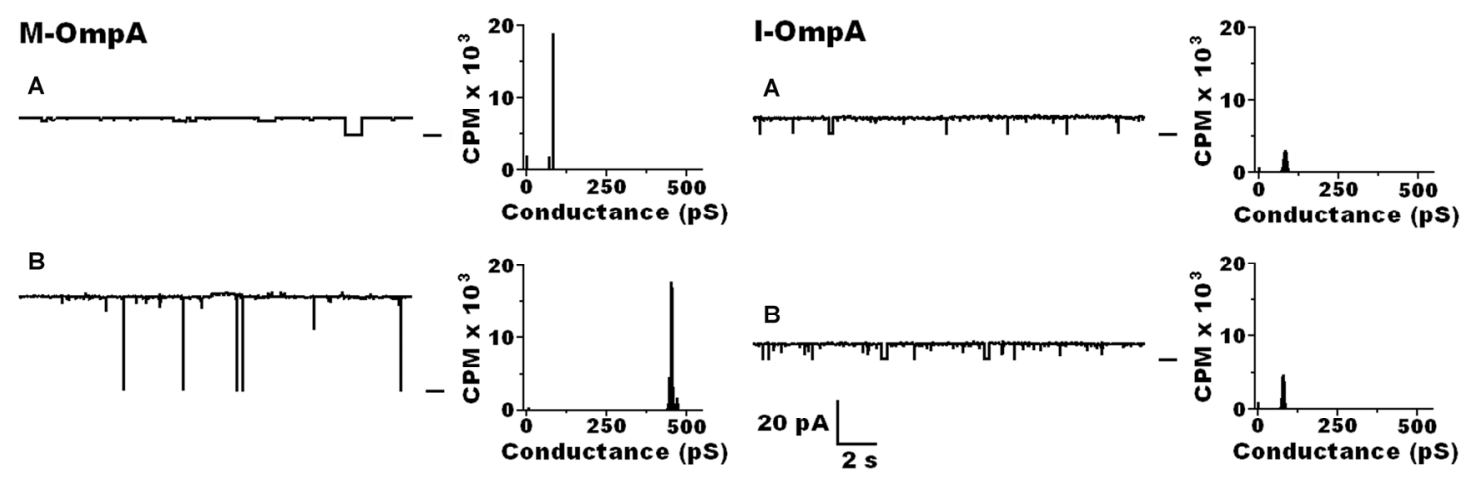

Once the conformational rearrangement has been completed, the large pore is very stable. The transformation is irreversible. Conversion of large pores to narrow pores with decreasing temperature was not observed. Even extended periods at low temperatures did not reverse the transition. Large pores are converted to narrow pores only when they are subjected to denaturing conditions. The sum of 
the data indicates strongly that the mature large pore structure is the end-product of the folding cascade (Figure 11).

Figure 11. Schematic drawing of the transition from a narrow $8 \beta$-barrel pore at lower temperatures to a large hypothetical $16 \beta$-barrel pore at higher temperatures. From Zakharian and Reusch Biochem 2005 [93].

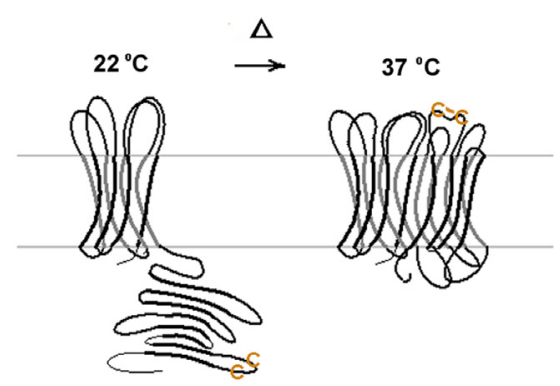

Although cPHB-modification is an effective process for increasing the hydrophobicity of polypeptide segments destined to remain within the bilayer, it may not be suitable for polar segments of the $C$-terminal domain that must traverse the bilayer to reach the extracellular aqueous medium. Another periplasmic modification that is also critical to the proper folding of OmpA is the formation of a disulfide bond between Cys290 and Cys302 of the $C$-terminal domain [46] by the oxidizing protein DsbA [106,107]. This modification clearly plays no role in the formation of the narrow pore by the $N$-terminal domain and thus it was considered to be irrelevant to the proper folding of the protein. In the Stathopoulos model of OmpA [90], residues 288-307 form a long extracellular loop (Figure 8). In addition to the Cys residues, this segment includes six charged residues (three positive and three negative). Molecular modeling studies by Negoda et al. [46] suggest that formation of a Cys290-Cys302 disulfide bond may facilitate bilayer transfer of this putative segment by enabling the formation of salt bridges between the oppositely charged residues and packaging it into a more compact structure (Figure 12). This conjecture is supported by planar bilayer studies [46], which showed that the Cys290-Cys302 disulfide bond was essential for OmpA to undergo the narrow-pore to large-pore transition, but it was not essential for retaining the large pore conformation once the transition has been completed.

From these studies, one may infer that the native structure of OmpA in E. coli is that of a single-domain large membrane pore, and that the two-domain structure is a folding intermediate that is unusually stable at lower temperatures. It is clear that cPHB-modification is essential to the formation of both the narrow pore and large pore conformations. Without cPHB modification of the $N$-terminal domain of OmpA in the cytoplasm, the narrow pore either does not form or it cannot fully insert into the bilayer; without cPHB modification of the $C$-terminal domain and creation of the Cys290-Cys302 disulfide bond in the periplasm, the large pore does not form. Studies of OmpA, which concluded that the native structure is a two-domain narrow pore, obtained the protein by overexpression [67,72-75,102,103], and thus it was lacking vital periplasmic modifications. Studies of OmpA, in which the large pore was observed, but only as a minor conformer, acquired the protein from the outer membranes but it was maintained at or below room temperatures $[89,90]$ or it was damaged by exposure to urea at elevated temperatures [91]. In summary, the folding of OmpA into its native structure requires that the protein 
undergo cPHB-modifications in both the cytoplasm and periplasm, disulfide bond formation in the periplasm AND, due to the temperature sensitivity of the cPHB backbone, it also requires physiological temperatures.

Figure 12. Molecular model of the longest extracellular loop formed by residues 288-307 of the $C$-terminal domain of OmpA [46]. Red: positive residues. Blue: negative residues. Yellow: Cys residues. The backbone is traced in green. Salt bridges are shown in gray ovals.

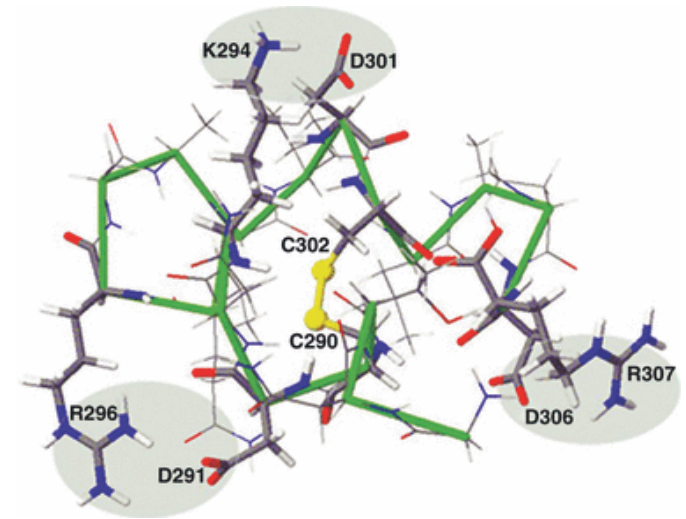

\section{Concluding Remarks}

cPHB constitutes yet another class of protein conjugates. This polyester is a ubiquitous constituent of both prokaryotic and eukaryotic cells in which it is primarily found covalently attached to proteins located within membranes and organelles. cPHB possesses physical properties that enable it to play important roles in the targeting, folding and function of these proteins. Clearly, the prospect of cPHB-modification should always be considered when designing protocols for isolating and refolding proteins for structural studies. Protein overexpression is a convenient method of obtaining ample amounts of protein for spectroscopic and crystallographic studies, but a functional protein is more than a chain of amino acids. Posttranslational modifiers of the protein should be identified and their potential roles in attaining the native structure carefully evaluated. In addition, it is important to realize that although the polypeptide structure of the protein is not strongly temperature-dependent, modifiers such as lipids and cPHB may make it so. Unless all temperature-dependent modifiers are ruled out, protein folding is best observed within the temperature range at which it occurs in nature.

\section{Acknowledgements}

The author would like to acknowledge support by NIH and NSF grants for research from her laboratory discussed herein, and the important contributions to these studies of Dieter Seebach and members of his laboratory at ETH, Zürich, and members of her research group, Linda Bramble, Ruiping Huang, April Gruhn, Yuri Shabalin, Sudipto Das, Eleonora Zakharian, Dongsheng Dai, Mo Xian, Alexander Negoda, Elena Negoda, and colleague Evgeny Pavlov.

\section{Conflict of Interest}

The authors declare no conflict of interest. 


\section{References}

1. Lemoigne, M. Produits de Dehydration et de Polymerisation de l'Acide B-oxobutyrique. Bull. Soc. Chim. Biol. 1926, 8, 770-782.

2. Anderson, A.J.; Dawes. E.A. Occurrence, metabolism, metabolic role, and industrial uses of bacterial polyhydroxyalkanoates. Microbiol. Rev. 1990, 54, 450-472.

3. Poli, A.; Donato, P.; Abbamondi, G.R.; Nicolaus, B. Synthesis, production, and biotechnological applications of exopolysaccharides and polyhydroxyalkanoates by Archaea. Archaea 2011, 2011, e693253.

4. Nuti, M.P.; de Bertoldi, M.; Lepidi, A.A. Influence of phenylacetic acid on poly- $\beta$-hydroxybutyrate (PHB) polymerization and cell elongation in Azotobacter chroococcum Beij. Can. J. Microbiol. 1972, 18, 1257-1261.

5. Pötter, M.; Steinbüchel, A. Poly(3-hydroxybutyrate) granule-associated proteins: Impacts on poly(3-hydroxybutyrate) synthesis and degradation. Biomacromolecules 2005, 2, 552-560.

6. Rehm, B.H. Genetics and biochemistry of polyhydroxyalkanoate granule self-assembly. Biothechnol. Lett. 2006, 28, 207-213.

7. Jendrossek, D. Polyhydroxyalkanoate granules are complex subcellular organelles (Carbanosomes). J. Bacteriol. 2009, 191, 3195-3202.

8. Elustondo, P.; Zakharian, E.; Pavlov, E. Identification of the polyhydroxybutyrate granules in mammalian cultured cells. Chem. Biodivers. 2012, 9, 2597-2604.

9. Reusch, R.N.; Sadoff, H.L. D-(-)-Poly- $\beta$-hydroxybutyrate in membranes of genetically competent bacteria. J. Bacteriol. 1983, 156, 778-788.

10. Reusch, R.N.; Hiske, T.W.; Sadoff, H.L. Poly- $\beta$-hydroxybutyrate membrane structure and its relationship to genetic transformability in Escherichia coli. J. Bacteriol. 1986, 168, 553-562.

11. Reusch, R.N. Poly- $\beta$-hydroxybutyrate/calcium polyphosphate complexes in eukaryotic membranes. Proc. Soc. Exp. Med. Biol. 1989, 191, 377-381.

12. Reusch, R.N.; Sparrow, A.W.; Gardiner, J. Transport of poly- $\beta$-hydroxybutyrate in human plasma. Biochim. Biophys. Acta 1992, 1123, 33-40.

13. Reusch, R.N. Biological complexes of poly- $\beta$-hydroxybutyrate. FEMS Microbiol. Lett. 1992, 103, 119-130.

14. Seebach, D.; Brunner, A.; Bürger, H.M.; Schneider, J.; Reusch, R.N. Isolation and ${ }^{1}$ H-NMR spectroscopic identification of poly(3-hydroxybutanoate) from prokaryotic and eukaryotic organisms. Eur. J. Biochem. 1994, 224, 317-328.

15. Reusch, R.N; Sadoff, H.L. Putative structure and functions of a poly- $\beta$-hydroxybutyrate/calcium polyphosphate channel in bacterial plasma membranes. Proc. Natl. Acad. Sci. USA 1988, 85, 4176-4180.

16. Reusch, R.N.; Huang, R.; Bramble, L.L. Poly-3-hydroxybutyrate/polyphosphate complexes form voltage-activated $\mathrm{Ca}^{2+}$ channels in the plasma membranes of Escherichia coli. Biophys. J. 1995, 69, 754-766.

17. Das, S.; Lengweiler, U.D.; Seebach, D.; Reusch, R.N. Proof for a nonproteinaceous calcium-selective channel in Escherichia coli by total synthesis from $(R)$-3-hydroxybutanoic acid and inorganic polyphosphate. Proc. Natl. Acad. Sci. USA 1997, 94, 9075-9079. 
18. Castuma, C.E.; Huang, R.; Kornberg, A.; Reusch, R.N. Inorganic polyphosphates in the acquisition of competence in Escherichia coli. J. Biol. Chem. 1995, 270, 12980-12983.

19. Huang, R.; Reusch, R.N. Genetic competence in Escherichia coli requires poly-beta-hydroxybutyrate/calcium polyphosphate membrane complexes and certain divalent cations. J. Bact. 1995, 177, 486-490.

20. Reusch, R.N. Transmembrane Ion transport by polyphosphate poly- $(R)-3$-hydroxybutyrate complexes. Bioch. Moscow. 2000, 65, 280-295.

21. Huang, R.; Reusch, R.N. Poly(3-hydroxybutyrate) is associated with specific proteins in the cytoplasm and membranes of Escherichia coli. J. Biol. Chem. 1996, 271, 22196-22202.

22. Reusch, R.N.; Huang, R.; Kosk-Kosicka, D. Novel components and enzymatic activities of the human erythrocyte plasma membrane calcium pump. FEBS Lett. 1997, 412, 592-596.

23. Reusch, R.N.; Shabalin, O.; Crumbaugh, A.; Wagner, R.; Schröder, O.; Wurm, R. Posttranslational modification of $E$. coli histone-like protein H-NS and bovine histones by short-chain poly-(R)-3-hydroxybutyrate (cPHB). FEBS Lett. 2002, 527, 319-322.

24. Reusch, R.N.; Bryant, E.M.; Henry, D.N. Increased poly-(R)-3-hydroxybutyrate concentrations in streptozotocin (STZ) diabetic rats. Acta Diabetol. 2003, 40, 91-94.

25. Reusch, R.N. Streptomyces lividans potassium channel contains poly- $(R)$-3-hydroxybutyrate and inorganic polyphosphate. Biochemistry 1999, 38, 15666-15672.

26. Xian, M.; Fuerst, M.M.; Shabalin, Y.; Reusch, R.N. Sorting signal of Escherichia coli OmpA is modified by oligo-(R)-3-hydroxybutyrate. Biochim. Biophys. Acta 2007, 1768, 2660-2666.

27. Zakharian, E.; Reusch, R.N. Haemophilus influenzae outer membrane protein A is associated with inorganic polyphosphate and polyhydroxybutyrate. Biophys. J. 2007, 92, 588-593.

28. Norris, V.; Bresson-Dumont, H.; Gardea, E.; Reusch, R.N.; Gruber, D. Hypothesis: Poly- $(R)-3$-hydroxybutyrate is a major factor in intraocular pressure. Med. Hypoth. 2009, 73, 398-401.

29. Seebach, D.; Fritz, M.G. Detection, synthesis, structure, and function of oligo(3-hydroxyalkanoates): Contributions by synthetic organic chemists. Int. J. Biol. Macromol. 1999, 25, 217-236.

30. Lehninger, A.L. Biochemistry; Worth Publishers Inc.: New York, NY, USA, 1970; p. 427.

31. Rueping, M.; Dietrich, A.; Buschmann, V.; Fritz, M.G.; Sauer, M.; Seebach, D. On the structure of poly(3-hydroxybutanoic acid) in solution and in phospholipid bilayers circular dichroism and fluorescence spectroscopy with oligo(3-hydroxybutanoic acid) derivatives. Macromolecules 2001, 4, 7042-7048.

32. Waser, P.; Rueping, M.; Seebach, D. On the solution structure of PHB: Preparation and NMR analysis of isotopically labelled oligo [(R)-3-hydroxybutanoic acids] (OHBs). Helv. Chim. Acta 2001, 84, 1821-1845.

33. Albert, M.; Seebach, D.; Duchardt, E.; Schwalbe,H. Synthesis and NMR analysis in solution of oligo(3-hydroxyalkanoic acid) derivatives with the side chains of alanine, valine, and leucine ( $\beta$-depsides): Coming full circle from PHB to $\beta$-Peptides to PHB. Helv. Chim. Acta 2002, 85, 633-658.

34. Gee, P.J.; Hamprecht, F.A.; Schuler, L.D.; van Gunsteren, W.F.; Duchardt, E.; Schwalbe, H.; Albert, M.; Seebach, D. A molecular dynamics simulation study of the conformational preferences of oligo-(3-hydroxyalkonoic acids) in chloroform solution. Helv. Chim. Acta 2002, 85, 618-632. 
35. Armand, M.B. Polymer Electrolyte Reviews-1; MacCallum, J.R., Vincent, C.A., Eds.; Elsevier Applied Science: New York, NY, USA, 1987; pp. 1-37.

36. MacCallum, J.R.; Vincent, C.A. Polymer Electrolytes Review-1; MacCallum, J.R., Vincent, C.A., Eds.; Elsevier: London, UK, 1987; pp. 23-37.

37. Gray, F.M. Solid Polymer Electrolytes; VCH: New York, NY, USA, 1992; pp. 1-4.

38. Seebach, D.; Bürger, H.M.; Plattner, D.A.; Nesper, R.; Fässler, T.F. Complexes of the triolide from $(R)$-3-hydroxybutanoic acid with sodium, potassium, and barium salts - Crystal structures, ester chelates and ester crowns, crystal packing, bonding, and electron localization functions. Helv. Chim. Acta 1993, 76, 2581-2601.

39. Bürger, H.M.; Seebach, D. Cation transport across bulk liquid organic membranes with oligomers of (R)-3-hydroxybutanoic acid. Helv. Chim. Acta 1993, 76, 2570-2580.

40. Seebach, D.; Brunner, A.; Büger, H.M.; Reusch, R.N.; Bramble, L.L. Channel-forming activity of 3-hydroxybutanoic-acid oligomers in planar lipid bilayers. Helv. Chim. Acta 1996, 79, $507-517$.

41. Fritz, M.G.; Walde, P.; Seebach, D. Oligoesters of ( $R$ )-3-hydroxybutanoic acid: Transmembrane transport of $\mathrm{Ca}^{2+}$ across lipid bilayers. Macromolecules 1999, 32, 574-580.

42. Zakharian, E.; Thyagarajan, B.; French, R.J.; Pavlov, E.; Rohacs, T. Inorganic polyphosphate modulates TRPM8 channels. PLoS One 2009, 4, e5404.

43. Zakharian, E.; Cao, C.; Rohacs, T. Gating of transient receptor potential melastatin 8 (TRPM8) channels activated by cold and chemical agonists in planar lipid bilayers. J. Neurosci. 2010, 30, 12526-12534.

44. Reusch, R.N.; Grühn, A.G. Poly(3-hydroxybutyrate)-Conjugated Proteins are Ubiquitous in Both Prokaryotes and Eukaryotes. In 1996 International Symposium Bacterial Polyhydroxyalkanoates; Eggink, G., Steinbüchel, A., Poirier, Y., Witholt, B., Eds.; NRC Research Press: Ottawa, Canada, 1997; pp. 10-19.

45. Karr, D.B.; Waters, J.K.; Emerich, D.W. Analysis of poly- $\beta$-hydroxybutyrate in Rhizobium japonicum bacteroids by ion-exclusion high pressure liquid chromatography and UV detection. Appl. Environ. Microbiol. 1983, 46, 1339-1344.

46. Negoda, A.; Negoda, E.; Reusch, R.N. Resolving the native conformation of Escherichia coli. FEBS J. 2010, 277, 4427-4437.

47. Dai, D.; Reusch, R.N. Poly-3-hydroxybutyrate synthase from the periplasm of Escherichia coli. Biochem. Biophys. Res. Comm. 2008, 374, 485-489.

48. Theodorou, M.C.; Panagiotidis, C.A.; Panagiotidis, C.H.; Pantazaki, A.A.; Kyriakidis, D.A. Involvement of the AtoS-AtoC signal transduction system in poly- $(R)$-3-hydroxybutyrate biosynthesis in Escherichia coli. Biochim. Biopys. Acta 2006, 1760, 896-906.

49. Kyriakidis, D.A.; Theodorou, M.C.; Filippo, P.S.; Kyriakidis, K.D.; Tiligada, E. Effect of histamine on the signal transduction of the AtoS-AtoC two component system and involvement in poly-(R)-3-hydroxybutyrate biosynthesis in Escherichia coli. Amino Acids 2008, 35, 45-52.

50. Theodorou, M.C.; Kyriakidis, D.A. Calcium channels blockers inhibit the signal transduction through the AtoSC system in Escherichia coli. Eur. J. Pharm. Sci. 2012, 47, 84-96.

51. Rychlewski, L.; Zhang, B.; Godzik, A. Functional insights from structural predictions: Analysis of the Escherichia coli genome. Prot. Sci. 1999, 8, 614-624. 
52. Saurin, W.; Hofnung, M.; Dassa, E.J. Getting in or out: Early segregation between importers and exporters in the evolution of ATP-Binding Cassette (ABC) transporters. Mol. Evol. 1999, 48, 22-41.

53. Wahab, H.A.; Khairudin, A.; Samian, M.R.; Najimudin, N. Sequence analysis and structure prediction of type II Pseudomonas sp. USM 4-55 PHA synthase and an insight into its catalytic mechanism. BMC Struct. Biol. 2006, 6, 6-23.

54. Jia, Y.; Kappock, T.J.; Frick, T.; Sinskey A.J.; Stubbe, J. Lipases provide a new mechanistic model for polyhydroxybutyrate (PHB) synthases: Characterization of the functional residues in Chromatium vinosum PHB synthase. Biochemistry 2000, 39, 3927-3936.

55. Smith, S.G.; Mahon, V.; Lambert, M.A.; Fagan, R.P. A molecular Swiss army knife: OmpA structure, function and expression. FEMS Microbiol. Lett. 2007, 273, 1-11.

56. Sonntag, I.; Schwarz, H.; Hirota, Y.; Henning, U. Cell envelope and shape of Escherichia coli: Mutants missing the outer membrane lipoprotein and other major outer membrane proteins. J. Bacteriol. 1978, 136, 280-285.

57. Morona, R.; Klose, M.; Henning, U. Escherichia coli K-12 outer membrane protein (OmpA) as a bacteriophage receptor: Analysis of mutant genes expressing altered proteins. J. Bacteriol. 1984, 159, 570-578.

58. Morona, R.; Krämer, C.; Henning, U. Bacteriophage receptor area of outer membrane protein OmpA of Escherichia coli K-12. J. Bacteriol. 1985, 164, 539-564.

59. Schweizer, M.; Henning, U. Action of major outer cell envelope membrane protein in conjugation of Escherichia coli K-12. J. Bacteriol. 1977, 129, 1651-1652.

60. Ried, G.; Henning, U. A unique amino acid substitution in the outer membrane protein OmpA causes conjugation deficiency in Escherichia coli K-12. FEBS Lett. 1987, 223, 387-390.

61. Belaaouaj, A.; Kim, K.S.; Shapiro, S.D. Degradation of outer membrane protein A in Escherichia coli killing by neutrophil elastase. Science 2000, 289, 1185-1188.

62. Soulas, C.; Baussant, T.; Aubry, J.F.; Delneste, Y.; Barillat, N.; Caron, G.; Renno, T.; Bonnefoy, J.F.; Jeannin, P. Outer membrane protein A (OmpA) binds to and activates human macrophages. J. Immunol. 2000, 165, 2335-2340.

63. Godefroy, S.; Corvaia, N.; Schmitt, D.; Aubry, J.P.; Bonnefoy, J.Y.; Jeannin, P.; Staquet, M.J. Outer membrane protein A (OmpA) activates human epidermal langerhans cells. Eur. J. Cell Biol. 2003, 82, 193-200.

64. Xie, Y.; Kim, K.J.; Kim, K.S. Current concepts on Escherichia coli K1Translocation of the blood-brain barrier. FEMS Immunol. Med. Microbiol. 2004, 42, 271-279.

65. Krishnan, S.; Prasadaroa, N.V. Outer membrane protein A and OprF: Versatile roles in Gram-negative bacterial infections. FEBS J. 2012, 279, 919-931.

66. Gonzalez Barrios, A.F.; Zuo, R.; Ren, D.; Wood, T.K. Hha, YbaJ, and OmpA regulate Escherichia coli K12 biofilm formation and conjugation plasmids abolish motility. Biotech. Bioeng. 2005, 93, 1-13.

67. Tamm, L.K.; Arora, A.; Kleinschmidt, J.H. Structure and assembly of $\beta$-Barrel membrane proteins. J. Biol. Chem. 2001, 276, 32399-32402. 
68. Schweizer, M.; Hindennach, I.; Garten, W.; Henning, U. Major proteins of the Escherichia coli outer cell envelope membrane interaction of protein II with lipopolysaccharide. Eur. J. Biochem. 1978, 82, 211-217.

69. Ried, G.; Koebnik, R.; Hindennach, I.; Mutschler, B.; Henning, U. Membrane topology and assembly of the outer membrane protein OmpA of Escherichia coli K12. Mol. Gen. Genet. 1994, 243, 127-135.

70. Koebnik, R. Membrane assembly of the E. coli outer membrane protein OmpA: Exploring sequence constraints on transmembrane $\beta$-strands. J. Mol. Biol. 1999, 285, 1801-1810.

71. Koebnik, R. Structural and functional roles of the surface exposed loops of the $\beta$-barrel membrane protein OmpA from Escherichia coli. J. Bacteriol. 1999, 181, 3688-3694.

72. Kleinschmidt, J.H.; Tamm, L.K. Secondary and tertiary structure formation of the $\beta$-barrel membrane protein OmpA is synchronized and depends on membrane thickness. J. Mol. Biol. 2002, 324, 319-330.

73. Vogel, H.; Jähnig, F. Models for the structure of outer membrane proteins of Escherichia coli derived from raman spectroscopy and prediction methods. J. Mol. Biol. 1986, 190, 191-199.

74. Arora, A.; Abildgaard, F.; Bushweiler, J.H.; Tamm, L.K. Structure of outer membrane protein A transmembrane domain by NMR spectroscopy. Nat. Struct. Biol. 2001, 8, 334-336.

75. Fernandez, C.; Hilty, C.; Bonjour, S.; Adeishvili, K.; Pervushin, K.; Wüthrich, K. Solution NMR studies of the integral membrane proteins OmpX and OmpA from Escherichia coli. FEBS Lett. 2001, 504, 173-178.

76. Pautsch, A.; Schulz, G.E. Structure of the outer membrane protein A transmembrane domain. Nat. Struct. Biol. 1998, 5, 1013-1017.

77. Pautsch, A.; Schulz, G.E. High-resolution structure of the OmpA membrane domain. J. Mol. Biol. 2000, 298, 273-282.

78. Bond, P.J.; Faraldo-Gomez, J.D.; Sansom, M.S. OmpA: A pore or not a pore? Simulation and modeling studies. Biophys. J. 2002, 83, 763-75.

79. Domene, C.; Bond, P.J.; Sansom, M.S. Membrane protein simulations: Ion channels and bacterial outer membrane proteins. Adv. Prot. Chem. 2003, 66, 159-193.

80. Gu, J.; Ji, X.; Qi, J.; Ma, Y.; Mao, X.; Zou, Q. Crystallization and preliminary crystallographic studies of the $C$-terminal domain of outer membrane protein A from enterohaemorrhagic Escherichia coli. Acta Crystallog. Sect. F. Struct. Biol. Cryst. Commun. 2010, 66, 929-931.

81. Song, J.H.; Lee, W.C.; Park, J.S.; Kim, S.I.; Lee, J.C.; Cheong, C.; Kim, H.Y. Cloning, purification and preliminary X-ray crystallographic analysis of the OmpA-like domain of peptidoglycan-associated lipoprotein from Acinetobacter Baumannii. Acta Crystllogr. Sect. F. Struct. Biol. Cryst. Commun. 2012, 68, 1351-1353.

82. Danoff, E.J.; Fleming, K.G. The soluble, periplasmic domain of OmpA folds as an independent unit and displays chaperone activity by reducing the self-association propensity of the unfolded OmpA transmembrane $\beta$-barrel. Biophys. Chem. 2011, 159, 194-204.

83. Rawling, E.G.; Martin, N.L.; Hancock, R.E.W. Epitope mapping of the Pseudomonas aeruginosa major outer membrane porin protein OprF. Infect. Immun. 1995, 63, $38-42$. 
84. Singh, S.P.; Williams, Y.U.; Miller, S.; Nikaido, H. The $C$-terminal domain of Salmonella enterica serovar Typhimurium OmpA is an immunodominant antigen in mice but appears to be only partially exposed on the bacterial cell surface. Infect. Immun. 2003, 71, 3937-3946.

85. Jeanteur, D.; Lakey, J.H.; Pattus, F. Bacterial Cell Wall; Ghuysen, J.M., Hakenbeck, R., Eds.; Elsevier Science: Amsterdam, The Netherlands, 1994; pp. 363-379.

86. Schirmer, T.; Cowan, S.W. Prediction of membrane-spanning $\beta$-strands and its application to maltoporin. Protein Sci. 1993, 2, 1361-1363.

87. Ferenci, T. From sequence alignment to structure prediction: The case of the OmpF porin family. Mol. Microbiol. 1994, 14, 188-189.

88. Stathopoulos, C. An alternative topological model for Escherichia coli OmpA. Prot. Sci. 1996, 5, 170-173.

89. Sugawara, E.; Nikaido, H. Pore-forming activity of OmpA protein of Escherichia coli. J. Biol. Chem. 1992, 267, 2507-2511.

90. Sugawara, E.; Nikaido, H. OmpA protein of Escherichia coli outer membrane occurs in open and closed channel forms. J. Biol. Chem. 1994, 269, 17981-17987.

91. Arora, A.; Rinehart, D.; Szabo, G.; Tamm, L.K. Refolded outer membrane protein A of Escherichia coli forms ion channels with two conductive states in planar lipid bilayers. J. Biol. Chem. 2000, 275, 1594-1600.

92. Zakharian, E.; Reusch, R.N. Outer membrane protein A of Escherichia coli forms temperature-sensitive channels in planar lipid bilayers. FEBS Lett. 2003, 555, 229-235.

93. Zakharian, E.; Reusch, R.N. Kinetics of folding of Escherichia coli OmpA from narrow to large pore conformation in a planar bilayer. Biochemistry 2005, 44, 6701-6707.

94. Reusch, R. Insights into the structure and assembly of Escherichia coli outer membrane A. FEBS J. 2012, 279, 894-909.

95. Bremer, E.; Cole, S.T.; Hindemach, I.; Henning, U.; Beck, E.; Kurz, C.; Schaller, H. Export of a protein into the outer membrane of Escherichia coli K12. Stable incorporation of the OmpA protein requires less than 193 amino-terminal amino-acid residues. Eur. J. Biochem. 1982, 122, 223-231.

96. Klose, M.; Schwarz, H.; MacIntyre, S.; Freudl, R.; Eschbach, M.; Henning, U. Internal deletions in the gene for an Escherichia coli outer membrane protein define an area possibly important for recognition of the outer membrane by this polypeptide. J. Biol. Chem. 1988, 263, 13291-13296.

97. Klose, M.; MacIntyre, S.; Schwarz, H.; Henning, U. The influence of amino substitutions within the mature part of an Escherichia coli outer membrane protein ompa on assembly of the polypeptide into its membrane. J. Biol. Chem. 1988, 263, 13297-13302.

98. Freudl, R.; Klose, M.; Henning, U. Export and sorting of the Escherichia coli outer membrane protein OmpA. J. Bioenerg. Biomembr. 1990, 22, 441-449.

99. Klose, M.; Storiko, A.; Stierhof, Y.-D.; Hindennach, I.; Mustschler, B.; Henning, U. Membrane assembly of outer membrane protein OmpA of E. coli. J. Biol. Chem. 1993, 268, 25664-25670.

100. Jendrossek, D.; Hendrick, R. Microbial degradation of polyhydroxyalkanoates. Annu. Rev. Microbiol. 2002, 56, 403-422. 
101. Negoda, A.; Negoda, E.; Reusch, R.N. Oligo-(R)-3-hydroxybutyrate modification of sorting signal enables pore formation by Escherichia coli. Biochim. Biophys. Acta 2009, 1798, 1480-1484.

102. Bulieris, P.V.; Behrens, S.; Holst, O.; Kleinschmidt, J.H. Folding and insertion of the outer membrane protein OmpA is assisted by the chaperone skp and by lipopolysaccharide. J. Biol. Chem. 2003, 278, 9092-9099.

103. Tamm, L.K.; Hong, H.; Liang, B. Folding and assembly of beta-barrel membrane proteins. Biochim. Biophys. Acta 2004, 1666, 250-263.

104. Mogensen, J.E.; Otzen, D.E. Interactions between folding factors and bacterial outer membrane proteins. Mol. Microbiol. 2005, 57, 326-346.

105. Ruiz, N.; Kahne, D.; Silhavy, T.J. Advances in understanding bacterial outermembrane biogenesis. Nat. Rev. Microbiol. 2006, 4, 57-66.

106. Collet, J.-F.; Bardwell, J.C.A. Oxidative protein folding in bacteria. Mol. Microbiol. 2002, 44, 1-8.

107. Ito, K.; Inaba, K. The disulfide bond formation dsb system. Curr. Opin. Struct. Biol. 2008, 18, $450-458$.

(C) 2013 by the authors; licensee MDPI, Basel, Switzerland. This article is an open access article distributed under the terms and conditions of the Creative Commons Attribution license (http://creativecommons.org/licenses/by/3.0/). 